\title{
Sexual Harassment, Assault, and Rape: College Students Report Their Experiences
}

\author{
Madeline Yzurdiaga \\ Undergraduate student at UCLA. She is on the Mock Trial team. \\ Keisha E. Payne, B.A. \\ Graduated from UCLA in 2014 with a B.A. in Sociology \\ Will be starting law school in the fall of 2016 \\ Jerome Rabow, PhD \\ $\mathrm{PhD}$ is a Professor Emeritus at UCLA, \\ Lecturer at California State University, Northridge \\ doi: 10.19044/esj.2016.v12n17p1 URL:http://dx.doi.org/10.19044/esj.2016.v12n17p1
}

\begin{abstract}
This paper reviews current research regarding sexual harassment, assault, and rape and its consequences. We examine different populations in varied settings and at different ages. We supplement this analysis with personal vignettes from college students who recall how and when their harassment and assaults occurred. Their experiences are shown to affect their views on gender, and gender relations.
\end{abstract}

Keywords: Sexual harassment, rape, assault, sexism, gender stereotypes, gender roles, gender relations, socialization, responses to assault male and female, assault consequences

\section{Introduction}

Definitions of sexual harassment range from legal to academic to the language of a victim. Although known extensively by women, sexual harassment itself has only been recently codified in law as a form of sexual discrimination under Title VII of the Civil Rights Act of 1964 (MacKinnon, 1979). This is shocking since sexual harassment was of concern to both abolitionists and social activists including Susan B. Anthony and Elizabeth Cady Stanton. The latter drew attention to the sexual coercion of slaves and domestic servants. Harassment was also a concern of the Women's Christian Temperance Movement (Reed, 2013). Studies of harassment report that almost 1 in 10 women left their job as a result of sexual harassment (U.S. Merit Systems Protection Board, 1981). One survey reports that $85 \%$ of girls and $76 \%$ of boys experience sexual harassment in schools (AAUW 1993, 
2001). In a randomly selected national sample of 4,446 college women in 1996 that looked at 12 types of harassment, $2.8 \%$ report having experienced attempted or completed rape. However, when the 2.8 percent victimization figure is calculated for a 1 year period, the data suggests that nearly 5 percent (4.9 percent) of college women are victimized in any given calendar year. Since a college career now lasts an lasts an average of 5 years the percentage of completed or attempted rape victimization among women in higher educational institutions might climb to between one-fifth and one-quarter (Fisher, 2000). Despite the extensiveness of harassment, it seems to be a largely ignored social phenomenon. In the words of MacKinnon (1979, p. 27), "Until 1976, lacking a term to express it, sexual harassment was literally unspeakable, which made a generalized, shared and social definition of it inaccessible".

The EEOC (Equal Employment Opportunity Commission) defines sexual harassment as "unwelcome sexual advances, requests for sexual favors, and other verbal or physical harassment of a sexual nature"; sexual harassment "does not have to be of a sexual nature, however, and can include offensive remarks about a person's sex" (United States EEOC, 2015). This legal definition allows courts to prosecute. Academic literature and college campuses define sexual harassment differently. Mackinnon $(1979,1)$ defines sexual harassment as any "unwanted imposition of sexual requirements in the context of a relationship of unequal power." The National Advisory Council on Women's Educational Programs defines it as "the use of authority to emphasize the sexuality or sexual identity of a student in a manner which prevents or impairs that student's full enjoyment of educational benefits, climate, or opportunities" (Till 1980, 7). Although seemingly straightforward, many definitions depend on the setting of said harassment, creating many operational denotations of sexual harassment. Moreover, many seem to be based upon a "continuum of behaviors", creating differing personal definitions of sexual harassment, which may contribute to the low reporting rates of women who have been sexually harassed (Bursik 1992; Magley, Hulin, Fitzgerald, \& DeNardo 1999; Sekreta 2006).

What is common to all these definitions is that sexual harassment is a product of environment, of gendered action, an invasion of privacy, a structural power struggle, and as a form of domination. Sexual harassment is an ongoing fact of life for many and can occur in a variety of settings ranging from public schools, public spaces, and the workplace.

This paper draws upon the experiences of college students who recall their experiences with the different types of harassment and the impact it had upon their view of gender and gender relations. We will neglect sexual 
harassment in the workplace as this setting has not been entered into by our sample of college students.

\section{Methods}

Students from two upper division classes (Dhillon, Rabow, Han, Maltz, and Moore, 2015) at two different public universities were asked to record their daily experiences with racism, sexism and homophobia. They described these experiences in their web posts, which were not monitored by the professor or the class facilitators. Additional written work required them to apply readings to their personal lives. We selected the web posts and written materials about gender which are the basis of the reported findings. When the class was over, we contacted students about using their written papers or their web posts. The students have approved all vignettes in this paper. The vignettes draw primarily on the time up until college but it is important to understand that both sexual harassment and assault occur throughout the life cycle as this will deepen our understanding of these phenomena.

\section{Sample}

The two classes had 65 students and we have used 26 vignettes from 24 students. No claims are made for the representation of the sample to the university wide population. The great majority of the students were social science majors. The sample may not have relevance for students in other countries.

\section{Results}

Youth

From an early age, men and women are taught how gender should be enacted in public and private spheres, with members of their own and the opposite sex and about the intricacies of power differentials often at play.

\section{Girls}

Girls are taught that sexual harassment is simply a part of life, an unavoidable result of being female. Sexual harassment is normalized to be “just boys being boys", treated as a consequence of biology rather than society. In the words of a young woman recalling her experiences in kindergarten, she is harassed to the point of silence, leaving her vulnerable and changed to this day:

"I remembered one occasion when $I$ was in kindergarten $I$ wore a skirt for picture day. I was standing in line to hand in work to my teacher, and this little boy named Jeremy pulled my zipper down on the side of my skirt. I was mortified. I tried really fast to zip it up but my underwear was 
getting in my way! I finally was able to fix my clothes without too much of a commotion. Something about that incident really traumatized me. To this day I cannot make sense of why it was okay for him to do that. I was too embarrassed to tell the teacher, scared even... Maybe this is one of the reasons why I did not like wearing skirts or dresses. I did not want to feel vulnerable or give anyone the opportunity to do that again."

Far from “normal”, this young woman's experience with her male classmate trying to pull down the zipper on her skirt illustrates the insidious consequences of sexual harassment. Although not causing too much of a "commotion" in her words, there still was "something" about the incident that "traumatized" her. Despite the fact that it is painted as every day, sexual harassment attacks the security of self, the feeling of comfort in one's own skin. Despite its seemingly harmless context, this mental assault is far from short-lived, as we see in her present dislike of skirts and dresses.

A student recalls her fourth grade experience with another female student who was called a "slut" because she had developed a bust:

"I remember in the fourth grade there was this girl named Jessica. Jessica was not called a 'slut' because she was a cheerleader but because she had fully developed bust. How do fourth grade boys come up with these ideas to put down girls? Why is it that something that is unique to women seen as something unnatural? Why should this young girl be picked on for her body type? She was accused of stuffing her bra; I suppose that was the root of the negative connotation, even though I do not believe she did so. Truth be told, starting in the sixth grade I knew at least one girl every year at school that stuffed their bras. One incident specifically, there was this girl named Christine who got caught by a classmate stuffing. To defend herself, she began telling the whole class that she had to put toilet paper in her bra because her nipples bled. It is crazy the pressure that women go through and that they feel the need to do things like this."

Labeled as a "slut" due to her early development of breasts, Jessica stands, as a model example of the "craziness" which this young woman so astutely notes seems to pervade the experiences of young women. The expectation that a young woman would be able to control her bodily development is absurd. Yet, another student, who suffered from her nipples bleeding, must quickly defend herself from being accused of "stuffing”. The conflicting societal pressure to be both a real "woman" with a fully developed body and not a "slut" illustrates the illogical expectations set up for young women.

A young woman describes her awareness of rape as a result of her elementary school peers.

"My parents were also protective of me. I knew that it was because I was a girl and from my teenage years I became very aware of the possibility 
of being raped. I had two friends who were raped during their elementary school years."

While we do not know the extent of harassment in public school among girls, we can conclude however that harassment is part of the public school environment.

\section{Boys}

From a young age, men are given privilege the right to be powerful solely based on their sex. As we can see in the following, gendered responsibilities of the household are engrained at childhood.

"My poor mother slaving away in a hot kitchen after been working all day, the sweat dripping from her brow, the stress building up in her shoulders, she was always tired, its natural the body can only take so much. And then to look over, and see my father laid flat of the couch, air conditioner right by his face, with a cold iced water, asking when diner is ready because he is hungry. You could see all the stress of his day leaving his body, as he relaxes watching television, and my mother is well into her second shift, the household shift. This is what it was growing up, the mere fact that women took care of the household, and did everything for the males in the house."

With no other model than his family, this man, although taught later to respect his mother and all women, was taught that to be masculine is to rest after work and relax with cool water. As a man, his own father had no "household shift". Instead, the stress of cooking and taking care of the household was delegated to the women of the home. These early lessons teach young boys where power lies in the home and how to reconstruct that model later in life.

However, young boys do not only model themselves after their fathers or other adult male figures in their lives but their own peers. Their masculinity is dependent on male peer assessment. For young men "the judgments of their male peers are critical to the measurement of how authentic they are at doing their masculinity" (Robinson 2006, 25). Young men must both figuratively and physically measure themselves in comparison to their friends and peers.

"I tended to follow the ideals of how boys should be due to influence by both my parents and due to the boys that were around me throughout elementary school. Some of the things that the boys did to other boys were to conduct some sort of "man check" among one another. They would ask each other questions among each other such as if they were heterosexual or not, and play games such as Mercy. Usually, the boys would refer to any other of the boys as something that would be seen as demeaning a male of his masculinity by calling him a "girl” or "faggot." Words such as "faggot" or 
"homo" were new to me in elementary since those were terms that were not used by my parents or my cousins when I was growing up. I remember I had to ask one of the guys in my class what those terms were and what they meant. I did whatever I could in elementary school to avoid being picked on by the boys that were in my class."

Sexual harassment for boys is an everyday tool used for humiliation and degradation and is a "male status builder" used to create connections between males in male peer groups (Robinson 2006, 29).

The following two vignettes illustrate humiliation, degradation and male status building.

"I especially remember, that I would make girls cry, simply to rub in their faces that they were more sensitive than boys. For some sick reason, this act made me feel tough, and cool. The fact that I had made a girl cry, and that she knew that she was sensitive and I was not, made me feel a sense of power. Perhaps this is due to the fact that when my friends and I got together, we would say how boys control women. How men, are strong, brave, and fierce leaders, like our fathers, who had their wives so well controlled, most of them never changed a single diaper for their children. Why you may ask? Because in their minds, men do not change diapers, that's a women's job. My friends saw gender as male and female. And each gender had a set of rules. Women wore pink, loud colors, while men wore black, blue and dark colors. Women played house, colored, and did their hair, while men played sports, had action figures, and loved cars and trucks. I remember I couldn't say I liked coloring when I was a child, because my friends would say that it was for girls. They would tease me and call me names, or think that I was homosexual. Yes my peers, and friends, would not refrain from calling me homosexual if I liked something out of the norm of what males were supposed to like. This would happen with movies, shows, and even colors. If a color wasn't a manly color so to speak was liked, a sure gay joke was next to follow. My friends not only helped give me guidelines to gender, they also made me homophobic for most of my adolescent years."

"I used to think what almost every guy I've ever known has thought: that girls wearing skimpy clothes are just doing it so they can get attention from guys, attention meaning sexual advances or groping. I used to hi-five my friends when they would perform some of these acts. This gave them support to actually perform groping, catcalls, and other inappropriate behavior. It was a common occurrence among my male friends to "cop-afeel," meaning quickly grope a woman, at concerts, clubs, and other places where it could be done anonymously. I didn't think about the women at all. They were just objects" 
There is a common pain rooted in sexual harassment. Young men and women who initiate or receive harassment participate in a limiting set of stereotypes, expectations and roles.

Despite the best efforts of parents, teachers, and mentors, sexual harassment and its paralyzing consequences accompany youths throughout their middle and high school years, negatively dominating adolescence.

\section{Adolescence}

Up until 1993, there had been little research done on sexual harassment involving young adolescents, mostly focusing on workplace and university sexual harassment (Corbett, Gentry, and Pearson, 1993). Indeed, many subjects in a study conducted on high school graduates, thought there was a "conspiracy of silence" regarding student-teacher sex in schooling (Wishnietsky, 1991). However, once studies were conducted, the results show a startling pattern of bullying transforming into sexual harassment.

A more recent national study conducted by the American Association of University Women (AAUW, 2011) found that $48 \%$ of all students, $40 \%$ of boys and $56 \%$ of girls reported sexual harassment experiences (Hand and Sanchez, 2000. Girls were significantly more likely to be targeted, with $56 \%$ of girls victimized compared to $40 \%$ of boys (AAUW 2011). In previous studies, the AAUW found that $81 \%$ of students were harassed occasionally and $27 \%$ targeted often, compared to less than a sixth of students reporting bullying (AAUW, 1993, 2001; Hand and Sanchez, 2000). Moreover, as grade level increased, so did sexual harassment, with only a $55 \%$ rate in $8^{\text {th }}$ and $9^{\text {th }}$ graders compared to $61 \%$ in $10^{\text {th }}$ and $11^{\text {th }}$ graders (AAUW,1993, 2001; Hand and Sanchez, 2000). It seems, with age comes a greater awareness of sexual harassment as a tool of power, especially for the primary perpetrators, young men (Robinson, 2006).

The most frequent form of sexual harassment experienced was verbal harassment (Leaper \& Brown 2009; Pepler, Craig, Connolly, Yuile, McMaster, Jiang, 2006). In particular, with male harassers, girls primarily experienced verbal, visual, and written sexual harassment (AAUW, 2011; Herbert, 1992; Larkin, 1994; Robinson, 1996).

"In Junior High School, our interest would develop through acts of checking out a woman together, to even cat calling. Not realizing how rude we were, it was something us males dominantly did as we have seen in pop culture like movies, the television or even other group of men."

Through this Filipino man's experience, we can see harassment viewed as an every day activity. In a study conducted in Australian secondary schools, this perception of cat calling was replicated by many young men, who saw sexual harassment as a joke, as normal, or as a 
behavior that girls "ask for" to gain attention (Robinson, 2006). Most saw sexual harassment as a whole as a "girl's issue", and thus not their problem.

\section{Girls}

The environment described in high school by a female is duplicated in the following count of a 14-year-old girl, who is leaving her school grounds to walk home,

"I was in the ninth grade walking back from school about three in the afternoon with a girlfriend, when a man in his late thirties driving past us, honked his horn. Our heads, of course, automatically turned and he proceeded to whistling at my friend and I and called out "hey pretty ladies." If this were to happen to me now, my blood would be boiling with anger but at this time, I had no idea what was happening. Before I could move, my friend ran across the street (she was three years older than I) when I noticed that the man was parking his car in a nearby parking lot. He quickly got out of his car and started walking towards me. I can still remember the horror I felt, as an innocent young teenager girl, when a man much older than I was crouching in front of me, staring me down, and signaling me to go towards him with his finger, in broad daylight. I was trembling with fear as I ran home. I was so afraid that I no longer wanted to walk home from school but I did not want to tell my parents because they might not let me ever go out alone."

As we further see in the example of a young woman who becomes pregnant in high school, the contradictory expectations of women have dire consequences:

"During my high school years I was on the soccer team with one of my best friends. She got pregnant and had to quit the team and soon after she left school. She told me that she was scared of the whole situation because her mom was very upset and blamed her for getting pregnant. Her mom would constantly threaten her with comments about sending her back to Mexico to live with her grandmother. This was not the case for the boy that got her pregnant. He was able to continue on as if nothing had happened. His life did not change at all. He was able to continue going to school and stay on the team he played for as well. Eventually she got tired of the whole ordeal and got an abortion and told me that it had been an awful experience. A few days after that, she told me that she was moving to Ensenada with her grandmother. I missed her a lot once she was gone."

Despite her boyfriend's complicity in her pregnancy, this young woman's friend has her future derailed by opposing expectations. She is both expected to be womanly in her appearance and manners, yet is punished when she is found with the product of her sexual activities. In contrast, her 
boyfriend faces no repercussions for his sexual exploits. It is no wonder that she is scared of her family's penalty for her.

\section{Boys}

Sexual harassment for boys is integral to male hegemony insuring their collective power over women (Robinson, 2006; Connell, 1996). In the next example, a young man in high school recalls the pressure he received from peers to harass young girls,

"My obligations in the peer groups were to abide by their norms and since it was high school days, sexual expression was rampant. This sexual expression at the time, took a form of hollering, objectifying, and the name calling of women in order to assert myself as "masculine" and gain the approval of my peers. My longing for approval and to assert myself as a "man" to my peers, also led to an energetic search for a girlfriend; and once achieved, full disclosure of intimacy to show prove of my virility and sexual drive."

A female who describes her view of male hegemony supplements the male's vignette. Boys can hoot and holler to show their sexual drive without adult intervention. If women were to perform their own femininity in a similar manner, they would be seen as overly sexual or labeled "slut" or "whore,"

"...if a girl slept around with different guys in high school, she was labeled a hoe. I had a friend who got the label of "slut" in the tenth grade. She had slept with several different guys at my high school and many students knew about her promiscuity. People would often call her names like "slut" and "hoe". I knew that she didn't like being called these names and that the name-calling made her act very depressed. I vowed to never be like her. Her experience taught me that if I don't want to get called derogatory names I better not sleep with too many different people. On the other hand, it was ok for boys to sleep with however many girls they wanted. I knew a boy that slept with at least four different people in the same school year. The only name I ever heard him being called was a player."

From this woman's account, we can see how sexual harassment is not a singular act but an ongoing process, to continually show one's virility. The privilege of masculinity must be constantly "reclaimed", for fear of being taken. In school, this plays out with male students forced to continually show their dominance as "men" through sexuality, while female students must resist all sexual encounters in order to be considered truly "female". These gendered double standards define not only the individual but also the peer group, as the bearers of gender definitions (Connell, 1987).

With sexual harassment as such an integral part of male peer groups, harassing women itself truly becomes an act by men for men; it is not 
necessarily about women at all but rather as a showing of male power within male groups, a way of "creating a sense of identity" that is lasting and overt, easily observable and quantified as to making measuring and thus judging it easier and more straightforward (Robinson 2006, 20). Although perhaps an exaggerated performance of masculinity, sexual harassment serves to show to the male self, his peers, and family his own authenticity of sex. By degrading the opposite sex, a young man demonstrates that he is capable of picking up the mantle of male privilege and using it for male gain, lifting himself up by lowering others. This early intervention into the male psyche perhaps gives us better insight to adolescent bullying and adult sexual harassment and its underlying causes and consequences.

\section{Young Adults}

With college deified in the media as the "golden years" of young adulthood, it should be no surprise that sexual harassment in academia is rarely talked about in public forums. Sexual harassment, whether it is between peers or student and teacher, is seemingly taboo, rarely discussed outside the pages of academic journals. Yet, to all those experiencing sexual harassment in higher education this form of "exploitation becomes deeply entangled in the educational process" (Cortina, Swan, Fitzgerald and Waldo, 1998, 422), a part of the collegiate experienced that is deeply engrained

It is estimated that 1 of every 2 female students is experiences some form of sexually harassing behavior during her years in school (Brooks \& Perot 1991), with $27 \%$ to $33 \%$ of undergraduate women reporting sexual assault while in college (Koss, Gidycsz, Wisniewski 1987). Other research reports higher statistics, with $76 \%$ of females and $36 \%$ of males reporting such behavior (Fitzgerald, Shullman, Bailey, Richards, Swecker, Gould, Omarod, and Weitzman, 1988). In a study conducted on both undergraduate and graduate female students, of the $50 \%$ of participants who did experience harassment, nearly two thirds described more than just one or two harassing incidents (Cortina, Swan, Fitzgerald and Waldo, 1998). Nonetheless, only $20 \%$ to $25 \%$ of victims of sexual harassment labeled what they experienced as “sexual harassing” (Cortina, Swan, Fitzgerald and Waldo, 1998). While some may view sexist putdowns and crude remarks as minor forms of sexual harassment, we believe that this is a misinterpretation of the experiences of the victims. It is the ongoing pressure to not think these behaviors as serious and consequential.

The perpetrators of sexual harassment at universities are professors and peers. Harassment done by professors aimed at their students illustrates the importance of the power dynamic in so many cases of sexual harassment (Murrell \& Dietz-Uhler, 1993). One study of undergraduates showed 55\% of 
women and 44\% of men experiencing sexual harassment at the hands of their teachers (Kalof, Ebby, Matheson, Krouska, 2001).

Why are college campuses the apparent breeding ground of sexual harassment and assault? Academic journals and scholars have conflicting pictures of the problem, some pointing to gender stereotyping and the reinforcement of female dependency at college and others to the maledominated atmosphere of higher education (Kalof, Ebby, Matheson, Krouska, 2001). Failure to recognize the extent of sexual assault on campus is provided by a survey of 647 college presidents with only $1 \%$ believing that the problem exists on their own campus and 8\% believing that is a problem for universities (Jaschik \& Lederman, 2015). When universities decide to do something about student rapists, less than one-third were expelled (Kinkade, 2014). What is clear is that sexual harassment is concentrated in this setting. "Sexual violence on campus has reached epidemic levels. During their first year in college, one in seven women will have experienced incapacitated assault or rape and nearly one in 10 will have experienced forcible assault or rape. Interventions to reduce sexual violence on campus are urgently needed." (Carey, Durney, Shepardson, \& Carey, 2015).

Women from the two campuses that were used in this study do not escape assault and rape.

"In my first year of college I, like many others, felt invincible. I went out and that night was probably the most horrific incident I've ever experienced, and yet I feel completely disconnected from it. The reoccurring nightmares for over a year were definitely no help in trying to forget about the sexual assault I suffered from. While at party that night, I ran into someone my friend's classmate. From the beginning I knew something was not right about talking to him, but I didn't pay any mind to my intuition. And my gut feeling was in overdrive when he asked me to go with him to get "more ice" for the beverages. Like an idiot, I decided to get into a moving vehicle with someone who had been drinking and most likely had other substances in his body. I silenced the feeling and went anyway. He turned on a dark street and proceeded to grab me. No matter how much I fought back, I knew it was pointless. Growing weaker and weaker with each struggle, I heard him repeating 'the easier you make this, the better it'll feel for you' and 'no one will believe you anyway.",

In the haunting prose of a recent assault victim, we find the evidence of a failure to address sexual harassment and assault at the college level. College-age women in particular are at a frighteningly high rate to be harassed and assaulted, with no seeming +end in sight; yet, too little is done to protect them. Male views about sexual assault still hold sway with men blaming the victim of sexual assault and rape rather than the perpetrator (Ryan, 1976). 
"When I was younger I fully believed that when a woman gets abused or attacked or raped it is because she put herself in that situation. I always wondered why my mom, for example, would date abusive men and why she couldn't just leave if she was getting hurt."

Another male while placing some responsibility on his close friend's actions as perpetrator, in the end, blames the victim.

"As is common thinking among males, I may have blamed her for being the victim. How stupid she was, I thought, to trust that guy. He made her keep drinking, and she should have seen the signs. I blamed him as well, and was disgusted by this guy did; the way he took advantage of her. He was supposed to be one of her best friends, and he showed that their friendship meant nothing to him, and that she meant nothing to him. Still, though, I thought that if she had just been smarter, not trusted him so much, that this could have been prevented. I now know that this was the wrong way to think about the situation."

\section{Racial and Ethnicity Issues in Academic Sexual Harassment}

Racial and ethnic minorities experience higher rates of harassment while in college and graduate schooling. With factors like lack of social power or capital, race-based stereotypes, minority status, cultural marginality, and economic vulnerability at play, many ethnic and racial minority status men and women find themselves in a uniquely stressful atmosphere (Kalof, Ebby, Matheson, Krouska, 2001; DeFour, 1990; MacKinnon, 1979). In all settings, this compounding of societal stressors can create a disadvantage for these vulnerable populations.

One study found that $62 \%$ of Black women, $60 \%$ of Hispanic women, and $46 \%$ of Asian and East Indian American women compared to $56 \%$ of White women experienced sexual harassment (Cortina, Swan, Fitzgerald and Waldo, 1998). Kalof (2001) found a prevalent stereotype of black women as "highly sexed" and who experienced harassment that focused on physical features and stereotypes of their promiscuity (Kalof, Ebby, Matheson, Krouska, 2001, 287). With white women, there was no such category reported or even included in past studies. The fascination with stereotyped “exotic women” extends into private and public spaces.

"As I got older men would catcall, whistle, flirt and ask for my number. As much as men would whistle and catcall, they would ask me the usual questions "Are you mixed?" "Is that your real hair?" Even though I am mixed, I identified only as black because most of the friends I hung out with were Black. I knew I did not look like some of the girls I hung out with at school because they were mostly dark skin and their hair was not as soft as mine. Even though I knew I was partly Latina, I did not speak Spanish so some of my Latina comrades did not want to be friends with me. I noticed 
that I got a lot more attention than my black or Latina friends from the guys at school and on the streets and I wondered why. I had a talk with one of my best friends and she told me because you are mixed you get a lot of attention from the guys. I was confused, so just because I have long hair and a curvy shape means that I can be harassed by perverts and get all the attention."

Due to this woman's unknown race, men in both school and in public spaces felt they could invade her personal space to "figure out" her true race. Her racially based physical features created the invitation for men to ask her demeaning questions that they deemed as harmless and curious manner, which she deemed as harassing. The intersection of race and gender presents us with a more complicated picture of sexual harassment and demand further research (Kalof, Ebby, Matheson, Krouska, 2001).

\section{Sexual Harassment for LGBTQI Teens}

Unique from the experience of heterosexual teenagers, sexual harassment against Lesbian Gay Bisexual Transgender Queer Intersex (LGBTQI) adolescents show an even more startling picture of the harmfulness of sexual harassment. Without widespread societal acceptance of their sexuality, LGBTQI teens face higher and higher rates of bullying and sexual harassment throughout their adolescence in school. One study of high school students showed that over half of LGBTQI students had been verbally harassed, almost a quarter were threatened with violence, and over ten percent had been physically attacked (D’Augelli, Pilkington, and Hershberger, 2002). LGBTQI sexual harassment is higher for males than females (Remafedi 1987; AAUW 1993; D’Augelli, Pilkington, and Hershberger, 2002). A national study of high school students by the American Association of University Women (1993) showed that of the 17\% of high school students who had been called gay or lesbian, more males (23\%) than females (10\%) were verbally harassed in this way. Another study of gay male youths found that over half experienced peer verbal abuse and nearly one-third reported physical assaults (Remafedi, 1987).

The forms of harassment also differ for homosexuals when compared to heterosexuals. In a national study, 20\% were threatened with the disclosure of their sexuality to others (D’Augelli, Pilkington, and Hershberger, 2002). Teens that were open with their sexuality to others were more victimized in high school, with those "coming out" earlier harassed even more (D’Augelli, Pilkington, and Hershberger, 2002). Indeed, openness about one's sexual orientation in high school and being gender atypical were significantly correlated with direct victimization ( D’Augelli, Pilkington, and Hershberger, 2002). 


\section{Rape}

"The ordinary response to atrocities" is to banish them from consciousness. Certain violations of the social compact are too terrible to utter aloud: this is the meaning of the word unspeakable." - Judith Lewis Herman, Trauma and Recovery (1997)

Count to 107. You can use “Mississippi's” or “alligator’s”. Just get to 107. In that time, another American in the United States has been sexually assaulted. Forty four percent of people that are sexually assaulted are under 18 years old, while $80 \%$ are under 30 . Among all victims, about nine out of ten are female (U.S. Department of Justice, 2007). One in six women and one in thirty three men have been the victim of attempted or completed rape in her or his lifetime (U.S. Department of Justice, 2007). In 2012 alone, there were 346,830 reported rapes or sexual assaults of persons 12 years or older (U.S. Department of Justice, 2012). Those not reported may far exceed that number.

The reason this section is separated from the others under the broad term of "sexual harassment" is because rape is irrevocably and indelibly different than other forms of sexual harassment.

In the United States and many other countries, a widespread lie has been perpetrated in the form of "rape culture". American society is described as such because "it fosters and encourages rape by teaching males and females that it is natural and normal for sexual relations to involve aggressive behavior on the part of males" (Herman, 1988). In essence, much like sexual harassment, sexual assault and rape have been partially normalized in our media, our schools, and in personal life. Rape is still very much an individual "victim's problem", rather than a societal one. Because victims often understand the stigma associated with rape, reported rates are low. In the United States only $16 \%$ of assaults are reported to the authorities (Kilpatrick, Renick, Ruggeiro, Conocenti, and McCauley, 2007). A multitude of factors could explain these low reporting rates, with victims and their situation unique from the next. Perpetrators are never eager to come forward and victims often feel hesitant and powerless. A young woman describes her own silence, as well as that of her mother.

"As little girls we aren't made to emotionally withstand the women's issue of rape, and although physical wounds heal, the psychological wounds of rape are almost close to impossible to cope with without help. But help isn't offered sometimes. Sometimes things like these get swept under the rug and become forbidden to talk about. I didn't want anyone to know, and I don't think my mother wanted to let anyone know either...It's like my mother and I had a silence about this rape because of the same reason, we didn't want to lose each other" 
This young woman, who points out the lack of help offered for sexual assault victims, points out an important aspect of rape reporting: upbringing. Although she understands the almost impossibility of dealing with the consequences of rape, this woman also knows that she cannot reveal the details of her rape in order to protect her family. As reflected in her later words, she was never taught to deal with rape, only to hide it:

"I was taught to be nice and kind, to be helpful around the kitchen, to watch out for my sister. I was taught the route to walk back home alone, I was taught the "safety words", I was taught how to behave, and to be a lady. I wasn't taught to protect myself. I wasn't taught to fight for myself. I wasn't taught to say no. I wasn't taught that, any of that, and as a young girl, I didn't know I had to arm myself. I was shy from ten years old when I experienced my first sexual encounter. His image haunts me to this day, my 10 year old self still very much quivers underneath the armor that my 23year-old self as created over the years. I didn't know it was wrong, although I felt very, very wrong. I don't remember saying no and I don't remember crying. But what I do remember, is remembering all the things I was taught as a young girl, were all point-blank naked lies."

Over a decade later, the inescapable and scarring results of rape still follows its victims. Despite her efforts to forget her experience, this woman still remembers the image of her attack, her young self quivering in her 23year-old body. All the lessons she was taught as a young girl to be a "woman" was useless in the monstrous face of sexual assault. Her experience relates and mirrors those of so many others, whose social, economic, and personal lives are forever altered.

\section{Consequences of Sexual Harassment}

The consequences of sexual harassment in adolescence ranged from physical, emotional, and psychological, affecting both school performance and personal life. Students reported a widespread loss of interest in regular activities and isolation from friends and family. Students who experienced sexual harassment reported negative psychosocial effects such as depression, loss of appetite, nightmares or disturbed sleep, low self esteem and feelings of being sad, afraid, scared, or embarrassed (AAUW, 1993 \& 2001; Hand and Sanchez, 2000; Lee, Croniger, Linn, and Chen, 1996). Their school performances declined including increased absenteeism, decreased quality of schoolwork, skipping or dropping classes, poor grades, tardiness and truancy (AAUW, 1993 \& 2001; Corbett, Gentry, and Pearson. 1993; Hand and Sanchez, 2000; Lee, Croniger, Linn, and Chen, 1996). Over one-fourth of LGBQTI students who have been sexually harassed reported that they had missed school in the last month, compared to 5\% of heterosexual students (Garofalo, Wolf, Kessel, Palfrey, and DuRant, 1998). 
Our students' reflections on their experiences with harassment confirm the impact of these events. A woman describes her being viewed by older males and internalizes a view of herself as dirty.

"When I walk into a grocery store in my community, I have learned to dress differently. Before when I went to the store in my pajamas I was stared at by older men who undressed me with their eyes. They made me feel so dirty and nasty I had to stop and cry before I entered the store. From that day on I tried my best to avoid eye contact with a man; I would wear two or three shirts to hide my breasts. I would wear big baggy clothes to hide my body. I hated my body and myself for receiving all the unwanted dirty attention, especially from older men. That was one of the topics I was looking to heal from, I wanted to feel proud of myself and not ashamed of my body."

In the next vignette, a woman describes the secret that she must keep and how she feels about herself.

"I feel dirty and I feel like it's my fault. I feel like if I told my parents, which I will NEVER EVER do, they wouldn't believe me, and they would blame me. I know that it's not my fault. I know... but I feel like it is. I'm ashamed. I feel unworthy of love and compassion. I feel dirty."

As we transition from high school to higher education, the intensity of sexual harassment and assault increases.

Women's experiences with sexual harassment in college were specifically associated with chronic psychological stress. Psychological stress, defined by Lazarus \& Folkman (1984, 21), can be explained as "a relationship between the person and the environment that is appraised by the person as taxing or exceeding his or her resources and endangering his or her well-being". Unlike acute or traumatic events, chronic stress and stressors last a longer period of time, with no definitive start or end. Thus, they can have an exceptional impact on a woman's psyche, as there seems to be no end to her victimization (DeLongis, Coyne, Dakof, Folkman \& Lazarus, 1982). In laymen's terms, sexual harassment acts much like a mental and psychological obstacle, blocking a woman's sense of safety and security in her own mind, especially in an academic setting like university schooling. At such a significant stage of personal and professional maturation, harassing behavior creates an irreversible scar so early in a woman's life.

Sexual harassment has been found over and over again to interfere with developmental tasks and threaten women's education, career, and income level (Huerta, Cortina, Pang, Torges, Magley, 2006). The aftermath of sexual harassment and assault affects all aspects of this student's life:

The next few weeks were the hardest. I couldn't face any of my friends from the shame. Looking at my family was unbearable. I spent weeks revisiting the moment in my head. His voice replayed in my head while I was 
trying to take my midterms, praying in church, and even as I cried myself to sleep."

Despite her best efforts to forget her attacker, this Latina woman must struggle through her daily life to even survive. Assault, especially in a college setting, makes academic achievement practically impossible. Victims of sexual harassment often experience depressed mood, anxiety, concentration difficulties, and diminished ambition, self-confidence, and self-esteem (Cleary, Schmieler, Parascesnco, Ambrosio, 1994). Some harassed women even have indications of Post Traumatic Stress Syndrome (Dansky \& Kilpatrick, 1997), experiencing symptoms of anger, degradation, violation, and betrayal, similar to sexual assault (Walker, Erickson, \& Woolsey, 1985). In higher education, this stress translates to higher rates of dropping classes, changing advisers, changing majors, and even dropping out of school all together (Fitzgerald, 1990; Bailey \& Richards, 1985; Fitzgerald, Shullman, Bailey, Richards, Swecker, Gould, Omarod, and Weitzman,; Reilly, Lott \& Gallogly 1986). This disengagement from an academic environment and subsequent performance decline represents an undue burden on those harassed. Notwithstanding their hard work and intellectual interest, victims of sexual harassment in higher education must battle to merely stay in school, much less excel in their given field.

\section{Consequences of Rape}

The consequences of rape remain in the lives of the assaulted for years. The thoughts of this rape survivor reveal a glimpse into the longstanding aftermath of a rape.

"If it was okay to talk about then maybe I would've been able to talk about and understand what had happened. To let me see that none of it was my fault nor anyone else. It took me almost ten years to realize that it's not healthy to think that this whole thing was my fault. People tell you that it's normal to feel upset, hurt, and angry. But they don't tell you how the rape rapes your every sense of trust and sexual safety."

What this woman so acutely points out is the lack of true awareness of the after effects of sexual assault.

The effects of rape are comparable to Post Traumatic Stress Syndrome (PTSD) (Nadelson, 1989). Rape can cause a survivor to have sleep disturbances and nightmares, headaches, diarrhea, uncontrollable crying, agitation and restlessness, increased use of drugs, and feelings of depression, guilt, and shame (Cohen and Roth, 1987; Frieze, Hymer, \& Greenberg, 1984; Janoff-Bulman \& Frieze, 1983a). Overall, survivors of sexual assault are likely to feel less trusting of others at a basic level (Bard \& Sangrey, 1979), causing distress and deterioration in personal relationships 
and problems in social and work adjustment (Frieze, Hymer, \& Greenberg 1984; Janoff-Bulman \& Frieze 1983a).

"I grew up in a single parent household and I felt protective of my mother worrying about the men that she dated. When she finally had a permanent live in boyfriend, I felt more secure but then I was sexually molested by him. I developed serious cognitive and psychological trust issues about men. My fear of men arose when I was 9 years old."

\section{Conclusion}

Sexual harassment and sexual assault in its many forms continue as an ongoing and persistent problem. Its persistence continues in part because of denial, but also because stereotypes about gender, patriarchy, and male privilege are embedded in social structure culture, and popular views. The compliance of actors who are witnesses to assault but diminish its seriousness also contributes to the persistence of harassment, assault and rape. Social actors in the institutions of school, family and peer groups can do something about denial, blaming the victim, and male privilege. Until the problem of harassment and rape is approached as system wide phenomena, it will continue. It is our hope that this paper contributes to the naming and identification of the problem, the recognition of its complexity, and awareness of the responsibility that we all have for these societal wide phenomena.

A young woman describes her first year of college life,

"In my first year of college life, I, like many others, felt invincible. I learned the reasons I was told to obey our parents...

That night was probably the most horrific incident I've ever experienced, and yet I feel completely disconnected from it. The reoccurring nightmares for over a year were definitely no help in trying to forget about the sexual assault I suffered from. While at party that night, I ran into someone my friend's classmate. From the beginning I knew something was not right about talking to him, but I didn't pay any mind to my intuition. And my gut feeling was in overdrive when he asked me to go with him to get "more ice" for the beverages. Like an idiot, I decided to get into a moving vehicle with someone who had been drinking and most likely had other substances in his body. I silenced the feeling and went anyway. He turned on a dark street and proceeded to grab me. No matter how much I fought back, I knew it was pointless. Growing weaker and weaker with each struggle, I heard him repeating 'the easier you make this, the better it'll feel for you' and 'no one will believe you anyway."' 


\section{References:}

American Association of University Women Educational Foundation. "Hostile hallways: The AAUW survey on sexual harassment in American schools". Washington, DC (1993): Harris/Scholastic Research.

American Association of University Women Educational Foundation. "Hostile hallways: Bullying, teasing and sexual harassment in school". Washington, DC (2001): American Association of University Women Educational Foundation. Web.

American Association of University Women Educational Foundation. “Crossing the Line: Sexual Harassment at School”. Washington, DC (2011): American Association of University Women Educational Foundation. Web.

Bailey, N., \& Richards, M. Tarnishing the ivory tower: Sexual Harassment in graduate training programs. Albany: State University of New York Press, 1985. Web.

Bard, M., \& Sangrey, D. The Crime Victim's Book. New York: Basic Books, 1979.

Brooks, L., \& Perot, A. R. "Reporting Sexual Harassment.” Psychology of Women Quarterly 15 (1991): 31-47. Web.

Bursik, K. "Perceptions of sexual harassment in an academic context." Sex Roles $27 \quad$ (1992): 401-412. Web.

Carey, K. B., Durney, S. E., Shepardson, R. L., \& Carey, M. P. (2015). Incapacitated and forcible rape of college women: Prevalence across the first year. Journal of Adolescent Health, 56(6), 678-680.

Cleary, J. S., Schmieler, C. R., Parascenzo, L. C., \& Ambrosio, N. "Sexual harassment of college students: Implications for campus health promotion." Journal of American College Health 43 (1994): 3-10. Web.

Cohen, L. J., \& Roth, S. "The Psychological Aftermath of Rape: Long-Term Effects and Individual Differences in Recovery." Journal of Social and Clinical Psychology 5 (1987): 525-534. Web.

Connell, R. W. Gender and Power. Stanford, CA: Stanford University Press, 1987.

Connell, R. W. "Teaching the boys: new research on masculinity, and gender strategies $\quad$ for schools.” Teachers College Record 98 (1996): 206-235. Web.

Corbett, K., Gentry, C. S., \& Pearson, W. "Sexual Harassment in High School.” Youth \& Society 25 (1993): 93-103. Web.

Cortina, L. M., Swan, S., Fitzgerald, L. F., \& Waldo, C. "Sexual Harassment and Assault: Chilling the Climate for Women in Academia." Psychology of Women Quarterly 22 (1998): 419-441. Web. 
Dansky, B., \& Kilpatrick, D. "Effects of sexual harassment." In W. O’Donohue (Ed.), Sexual harassment: Theory, research, and treatment. Needham Heights, MA: $\quad$ Allyn \& Bacon, 1997.

D’Augelli, A. R., Pilkington, N. W., \& Hershberger, S. L. "Incidence and Mental Health Impact of Sexual Orientation Victimization of Lesbian, Gay, and Bisexual Youths in High School.” School Psychology Quarterly 17 (2002): 148-167. Web.

DeFour, D. C. "The interface of racism and sexism on college campuses.” In Sexual harassment on college campuses: Abusing the ivory power, edited by Michelle A. Paludi. Albany: State University of New York Press, 1990. Web

DeLongis, A., Coyne, J. C., Dakof, G., Folkman, S., \& Lazarus, R. S. (1982).Relationship of daily hassles, uplifts, and major life events to health status.Health psychology, 1(2), 119.

Dhillon, M., Rabow, J., Han, V., Maltz, S., \& Moore, J. (2015). Achieving Consciousness and Transformation in the Classroom: Race, Gender, Sexual Orientations and Social Justice. Sociology Mind, 5(02), 74.

Fisher, B. "The Sexual Victimization of College Women.” NCJ 182369, 2000. Web.

Fitzgerald, L. F. (1990). Sexual harassment: The definition and measurement of a construct. Ivory power: Sexual harassment on campus, 21(22), 24-30.

Fitzgerald, L. F., Shullman, S. L., Bailey, N., Richards, M., Swecker, J., Gold Y., Ormerod, M., \& Weitzman, L. "The incidence and dimensions of sexual harassment in academia and the workplace.” Journal of Vocational Behavior 32 (1988): 152-175. Web.

Frieze, I. H., Hymer, S., \& Greenberg, M. S. "Describing the victims of crime and violence.” In A. Kahn (Ed.), Victims of crime and violence: Final report of the APA Task Force on the Victims of Crime and Violence. Washington, DC: American Psychological Association, 1984.

Garofalo, R., Wolf, R. C., Kessel, S., Palfrey, J., \& DuRant, R. H. “The association between health risk behavior and sexual orientation among a school-based sample of adolescents.” Pediatrics 101 (1998): 895-902.

Hand, J. Z., \& Sanchez, L. "Badgering or Bantering? Gender Differences in Experience of, and Reactions to, Sexual Harassment among U.S. High School Students.” Gender \& Society 14 (2000): 718-746. Web.

Herbert, C. Sexual Harassment in Schools: A Guide For Teachers. London: David Fulton, 1992.

Herman, D. F. “The Rape Culture.” Culture 1(10) (1988). Web.

Herman, J. L. (1997). Trauma and recovery. Basic books.

Huerta, M., Cortina, L. M., Pang, J. S., Torges, C. M., \& Magley, V. J. (2006). Sex and power in the academy: Modeling sexual harassment in the 
lives of college women. Personality and Social Psychology Bulletin, 32(5), 616-628.

Janoff-Bulman, R. \& Frieze. I. H. (Eds.). "Reactions to victimization." Journal of Social Issues 39(2) (1983a). Web.

Jaschik, S. \& Lederman, D. “The 2015 Inside Higher Ed Survey of College and University Presidents.” (2015)

Kalof, L., Eby, K. K., Matheson, J. L., \& Kroska, R. J. “The Influence of Race and Gender on Student Self-Reports of Sexual Harassment by College Professors.” Gender \& Society 15 (2001): 282-302. Web.

Kilpatrick, D. G., Renick, H. S., Ruggiero, K. J., Conoscenti, L. M., \& McCauley, M. S. "Drug-facilitated, Incapacitated, and Forcible Rape: A National Study.” Charleston, S.C.: National Crime Victims Research \& Treatment Center, 2007. Web.

Kingkade, T. "Fewer Than One-Third Of Campus Sexual Assault Cases Result In Expulsion.” Huffington Post. (2014) http://www.huffingtonpost.com/2014/09/29/campus-sexualassault_n_5888742.html Web.

Koss, M. P., Gidycz, C. A., \& Wisniewski, N. “The scope of rape: Incidence and prevalence of sexual aggression and victimization in a national sample of higher education students." Journal of Consulting and Clinical Psychology 55 (1987): $162-170$. Web.

Larkin, J. Sexual Harassment: High School Girls Speak Out. Toronto: Second Story Press, 1994.

Lazarus, R. S., \& Folkman, S. Stress, appraisal and coping. New Yorker: Springer, 1984.

Leaper, C., \& Brown, C. S. "Perceived experiences with sexism among adolescent girls.” Child Development 79 (2009): 685-704. Web.

Lee, V., Croniger, R. G., Linn, E., \& Chen, X. "The culture of sexual harassment in secondary schools.” American Educational Research Journal 33 (1996): 383-417. Web.

MacKinnon, C. Sexual Harassment of Working Women. New Haven: Yale University, 1979.

Magley, V. J., Hulin, C., Fitzgerald, L.F., \& DeNardo, M. (1999). "Outcomes of self- labeling sexual harassment”. Journal of Applied Psychology 84 (1999): 390-402. Web.

Murrell, A. J., \& Dietz-Uhler, B. L. "Gender Identity and Adversarial Sexual Beliegs as Predictors of Attitudes Toward Sexual Harassment." Psychology of Women Quarterly 17 (1993): 169-175. Web.

Nadelson, C. C. "Consequences of Rape: Clinical and Treatment Aspects." Psychother Psychosom 51 (1989): 187-192. Web. 
Pepler, D. J., Craig, W. M., Connolly, J. A., Yuile, A., McMaster, L., \& Jiang, D. "A Developmental Perspective on Bullying." Aggressive Behavior 32 (4) (2006): 376-384. Web.

Reed, Amanda (2013). A Brief History of Sexual Harassment in the United States, http://now.org/blog/a-brief-history-of-sexual-harassment-in-theunited-states/

Reilly, M. E., Lott, B., \& Gallogly, S. M. "Sexual harassment of university students.” Sex Roles 15 (1986): 333-358. Web.

Remafedi, G. "Male homosexuality: The adolescent's perspective." Pediatrics 79 (1987): 326-330. Web.

Robinson, K. H. “Classroom discipline: power, resistance and gender. A look at teacher perspectives.” Gender and Education 4(3) (1996); 273-287. Web.

Robinson, K. H. "Reinforcing hegemonic masculinities through sexual harassment: issues of identity, power and popularity in secondary schools.” Gender and Education 17 (2006): 19-37. Web.

Ryan, W. (1976). Blaming the victim (Vol. 226). Vintage.

Sekreta, E. "Sexual harassment, misconduct, and the atmosphere of the laboratory: The legal and professional challenges faced by women physical science researchers at educational institutions.” Duke Journal of Gender Law and Policy 13 (2006): $\quad$ 115-137. Web.

Till, F. J. "Sexual Harassment. A Report on the Sexual Harassment of Students.” National Advisory Council on Women's Educational Programs (1980): Washington, D.C. Web.

United States Department of Justice. "Criminal Victimization in the United State, 2007 Statistical Tables.” Washington DC (2007): Bureau of Justice Statistics. Web.

United States Department of Justice. "National Criminal Victimization Survey, 2012 Statistical Tables.” Washington DC (2012): Bureau of Justice Statistics. Web.

United States Equal Employment Opportunity Commission [EEOC]. "EEOC Charge Receipts by State (includes U.S. Territories) and Basis for 2013." EEOC Charge Receipts by State (includes U.S. Territories) and Basis for 2013 (2013).

United States Equal Employment Opportunity Commission [EEOC]. "EEOC Charge Receipts by State (includes U.S. Territories) and Basis for 2015." EEOC Charge and Basis for 2015 (2015). Web.

United States Merit Systems Protection Board. Sexual harassment of federal works: Is it a problem? Washington, DC (1981): U.S. Government Printing Office. 
Walker, G., Erickson, L., \& Woolsey, L. "Sexual harassment: Ethical research and clinical implication in the academic setting." International Journal of Women's Studies 8 (1985): 424-433. Web.

Wishnietsky, D. H. "Reported and unreported teacher-student sexual harassment.” Journal of Educational Research 84 (1991): 164-169. Web. 